\title{
Sustainability Performance in Supply Chain of Dairy Products: Examining the Constraints of Dairy Sector Using Value Chain Approach in Northern Regions, Tanzania
}

\author{
Catholic Sumuni \\ Department of Business Management, Institute of Accountancy Arusha, P.o. Box 2798, Arusha, Tanzania
}

\begin{abstract}
The aim of this study was to investigate the sustainability performance in supply chain of dairy products in Tanzania. The study conducted in Simanjiro district using cross-sectional survey method and focus group discussions. The findings of this study show that processing facilities, access to market, storage facilities, distribution and delivery system are the main enormous supply chain constraints which affect the sustainability performance of diary sector. This study recommends that in order to ensure sustainable performance of dairy sector, a multidisciplinary approach, value chain techniques, diverse strategies and dialogues should be taken involving all key actors (i.e. LGA's, civil society, respective ministries, smallholders' farmers, processing firms, and dairy entrepreneurs).
\end{abstract}

Keywords: Dairy sector, Sustainable performance, Supply chain, Value chain

DOI: $10.7176 / \mathrm{EJBM} / 11-32-11$

Publication date: November $30^{\text {th }} 2019$

\section{Introduction}

Dairy sector is paramount sector for the economic development in sub-Saharan Africa (Ahmed, Ehui, \& Assefa, 2004). The Eastern Africa is the leading of dairy producers in the continent. Approximately $68 \%$ of dairy products of the continent comes from Ethiopia, Kenya and Tanzania (Bingi \& Tondel, 2015). It is estimated that the dairy sector contributed 9-14\% of East Africa's agricultural gross development product (Lukuyu, Blanchard, \& Rowley, 2019). For Tanzania, the dairy sector is important component of the livestock sector which contributes about $1 / 3$ of the $4.6 \%$ livestock industry's contribution to the GDP (Nelgen \& Strutt, 2014; Njombe, Msanga, Mbwambo, \& Makembe, 2011). On value added context, the industry accounts for $28-30 \%$ of value added and in overall it accounts $30 \%$ of the livestock contribution to agricultural GDP (Katjiuongua \& Nelgen, 2014).

Despite the tremendous contribution of dairy sector at country level, the sector is facing a number of impediments in supply chain spectrum from downward to upward stream which dwindle the sustainability performance. Some of the prominent challenges include regulatory challenges like multiple inspections, multiple testing of products, multiplicity of licenses and bureaucratic roadblocks during transportation (Charles Urassa, 2014). Other cited constraints include lack of reliable markets, lack of infrastructure for input and output markets, unfavorable taxation policies, poor flow of information, restricted access to credit for small scale holders (E. S. Swai \& Karimuribo, 2011). On value chain context, the sector is bounded by poor quality of milk, poor processing and production system, poor storage system and fragmented markets (Kilelu et al., 2017; Maleko, Msalya, Mwilawa, Pasape, \& Mtei, 2018).

While there are numerous past studies that explored the sustainability performance of dairy supply chain in global context (Bourlakis, Maglaras, Gallear, \& Fotopoulos, 2014; Ding, Fu, Zheng, \& Yan, 2019; Ghadge, Kaklamanou, Choudhary, \& Bourlakis, 2017; Glover, Champion, Daniels, \& Dainty, 2014; Kazancoglu, OzkanOzen, \& Ozbiltekin, 2018; Mor, Bhardwaj, \& Singh, 2018; Nicholson, Gómez, \& Gao, 2011; Prakash, Soni, Rathore, \& Singh, 2017; Svensson \& Wagner, 2012), little have been done in Tanzania. The dearth of published empirical evidence which examined the sustainability performance of dairy supply chain in Tanzania enforce and motivate the researcher to conduct this study. This study guided by the following research question: $R Q$ : Which supply chain activities affect the sustainability performance of dairy sector involving smallholder farmers in Tanzania?

This paper is organized in four (4) sections as follows. First, the review of literature related Sustainability performance in supply chain of dairy products; Second, discussion on the research methods is provided. Third, presentation of the results and discussion of findings. Lastly, the researcher provides theoretical, managerial implications and research limitations, and suggestions for future research directions.

\section{Literature review and theoretical background}

2.1 Value chain approach (VCA)

This study employed the value chain approach. The value chain framework is widely and prominent framework in the studies of food supply chain (Hawkes, Blouin, Henson, Drager, \& Dubé, 2009). A value chain is defined 
as a linked sequence of activities in which each activity and its stage in the value chain adds value to the product or service in question, a value for which the end consumer is willing to pay (Faulconbridge, 2007).

According to Kilelu et al. (2017), value chain framework is increasingly promoted as holistic intervention frameworks for inclusive smallholder development in evolving agri-food markets in Sub-Saharan Africa. VCA is integrated with multi-stakeholder processes to facilitate the value chain upgrading of smallholders which originate from a wide perspective of global value chain framework (Kilelu et al., 2017). The framework is proclaimed to be keen in improving overall value of small scale farmers in supply chain of agri-food (Taylor, 2005).

Value chain approach is a generic concept which is applicable in a diversified areas like agriculture (Francis, Simons, \& Bourlakis, 2008; Howieson, Lawley, \& Hastings, 2016; Kline et al., 2016; Rudenko, Grote, \& Lamers, 2008; Savino, Manzini, \& Mazza, 2015; Sharma \& Christie, 2010; Taylor, 2005), productions economics (Dahlström \& Ekins, 2006; Henderson, Dicken, Hess, Coe, \& Yeung, 2002), operational management (Fearne, Garcia Martinez, \& Dent, 2012), marketing management (Crain \& Abraham, 2008; Donaldson, Ishii, \& Sheppard, 2006), engineering (Rabelo, Eskandari, Shaalan, \& Helal, 2007), strategic management (Bolwig, Ponte, Du Toit, Riisgaard, \& Halberg, 2010; Hergert \& Morris, 1989) etc. The application of value chain perspectives as a persuasive approach in facilitating sustainability of supply chain of dairy is divulged in extant past literatures (Binder, Schmid, \& Steinberger, 2012; Bourlakis et al., 2014; Kilelu et al., 2017).

\subsection{Sustainability of dairy products in Tanzania}

Sustainability is an important agenda in modern agri-business. In agricultural perspective, sustainability can be referred to situation in which the agricultural sector continues to meet demand for food indefinitely while incurring farm-level economic and environmental costs that societies find acceptable (Anderson, 2019). Rose et al. (2019) argue that "sustainable agriculture intend to balance the economic, environmental, and social aspects of farming, creating a resilient farming system in the long-term". Global warming, scarcity of resources, starvation, and drought has made a drastically changes in thinking of sustainability in agri-food supply chain for future generation and society (El Semary, 2019).

In today world, sustainable agriculture is inevitable (Gafsi, Legagneux, Nguyen, \& Robin, 2006). As the world concern and attention is on the climate changes, Tanzania is not excluded (Omambia \& Gu, 2010). Agriculture is a life blood and economic back born of Tanzania (Manyilizu et al., 2016; Temu, 2011). As mentioned earlier, dairy sector is one among the important contributor of agricultural GDP of Tanzania, the sustainability of the sector should be a concern of every one (Kimaro, Mor, \& Toribio, 2018; Maleko et al., 2018). Despite the fact that, smallholder dairy farming is growing at steady rate of $6 \%$ per year and climate are appropriate in majority parts of Tanzania but the supply of milk and milk products has not kept pace with the rapid increase in the human population (E. S. Swai \& Karimuribo, 2011).

Northern zone of Tanzania is characterized as the leading region having large number of smallholder dairy farming (Kurwijila \& Henriksen, 1995). However, there are number of challenges which face the smallholder dairy farming in northern part of Tanzania which rise the alert on the sustainability of the sector. Some of the issues include land scarcity (Hillbom, 2011), dry season fodder scarcity (and access to water) for cattle kippers (Kurwijila, Omore, \& Grace, 2012; Maleko et al., 2018), rise in temperature, prolonged and frequent periods of drought in the regions (Kimaro et al., 2018), massive cattle deaths due to outbreaks of diseases (Kimaro et al., 2018; Ojija, Abihudi, Mwendwa, Leweri, \& Chisanga, 2017) and etc.

\subsection{Upgrading value chain of dairy products in Tanzania}

Upgrading refer to how firm produce a better product, making them more efficiently or moving into more skilled activities and improving their performance and rewards in high-value markets (Giuliani, Pietrobelli, \& Rabellotti, 2005). In agricultural context, upgrading in value chain is a very common concept which enhance the overall improvement of smallholder in downward-upward stream of supply chain. Humphrey and Schmitz (2002) emphasized and come up with typology which smallholder should be concerned as the upgrading strategy: First is process upgrading, second is product upgrading, third is functional upgrading and last is intersectoral/interchain upgrading.

According to Kilelu et al. (2017) upgrading value chain of dairy products in Tanzania need four comprehensive strategies (1) improving value chain coordination, this include vertical and horizontal coordination (Bolwig, Ponte, Riisgaard, du Toit, \& Halberg, 2013) (2) improving process and product, this involve the process upgrade (i.e. reduce production cost) as well the product upgrade (i.e. improve quality) (3) changing and adding functions, this include functional upgrading as well the inter-chain upgrading and (4) upgrading the institutional environment, this involve the upgrading of the institutional organs that constrains the value chain of smallholders like support services, legal and policy frameworks (Charles Urassa, 2014). 


\subsection{Supply chain constraints of dairy products in Tanzania}

Supply chain is defined as a "set of three or more entities (organizations or individuals) directly involved in the upstream and downstream flows of products, services, finances, and/or information from a source to a customer" (Mentzer et al., 2001). Christopher (2016) define supply chain as the network of organizations that are involved, through upstream and downstream linkages, in the different processes and activities that produce value in the form of products and services delivered to the ultimate consumer. In agriculture context, the supply chain involved the multiple players, the upstream part (i.e. smallholders, processing firms) and the downstream part (i.e. distribution and ultimate consumers). There are extant of literatures which investigate the challenges and constraints that affect food supply chain worldwide (Bhagat \& Dhar, 2011; Chang, Droli, \& ISEPI, 2014; Vasileiou \& Morris, 2006), but not much have been explored the in the dairy sector (Nicholson et al., 2011).

Tanzania like any other developing country, agriculture supply chain is facing enormous constraints that affect its sustainability (Ruteri \& Xu, 2009). The constraints effect on both side of the spectrum (upward and downward). Dairy sector as one of the agricultural part is facing a number challenges in Tanzania, some common constraints include poor storage facilities (Kurwijila, Omore, Staal, \& Mdoe, 2006; Ruteri \& Xu, 2009), poor processing facilities (Schoder, Maichin, Lema, \& Laffa, 2013), poor transportation system and physical infrastructures (Jeckoniah, Mdoe, \& Nombo, 2013), poor distribution and delivery system (Kivaria, Noordhuizen, \& Kapaga, 2006), access and informal market barrier (Eskola, 2005; Kilelu et al., 2017).

\section{Methodology}

Simanjiro district was selected for this study due to plenty of reasons (1) it is recognized as the third district in Manayara region with large number of smallholder dairy farmers including cattle keepers and small milk processing units (URT, 2012) and (2) it is mentioned as the one of the Maasai pastoral area which experienced severe climate changes and need effective sustainable framework for long term survival (Sewando, Mutabazi, \& Mdoe, 2016; Watkiss et al., 2011). Furthermore, due to the nature of this study, Arusha municipal was selected as the downstream strategic point and milk market area which originate from Simanjiro district (Hillbom, 2011). This study persuaded two main research methods (1) cross-sectional survey method and (2) focus group discussions. The cross-sectional survey method was employed which involved all key informants in this study by collecting information out at one time point or over a short period (Levin, 2006). The method was appropriated as recommended in the contemporary agricultural studies (Kilelu et al., 2017; Kivaria et al., 2006; E. Swai et al., 2005). Another complementary method that used in this study was focus group discussions. Focus group discussion was conducted to some specific representative of the respondents involved in this study including key actors-farmers, collectors, processors and consumers of dairy products. The FGD included all key participants involved in the supply chain of dairy from the upward stream to downward stream in Simanjiro district. The Focus group discussions was conducted between January - March 2019 using Swahili language and translated back into English language by language experts.

Table1. Dairy mapping profile

\begin{tabular}{lc}
\hline Characteristics & Number $(\%)$ \\
\hline Respondents & \\
Pastoralists & $70(35.5 \%)$ \\
Traders (retailers \& wholesaler) & $30(15.2 \%)$ \\
Processing firms & $7(3.6 \%)$ \\
Consumers (small \& bulk) & $90(45.7 \%)$ \\
Gender of Pastoralists & \\
Male & $19(27.1 \%)$ \\
Female & $51(72.9 \%)$ \\
Milk producer's capacity (In liters) & \\
$\leq 5$ liters & $31(44.3 \%)$ \\
$6-10$ liters & $20(28.6 \%)$ \\
$11-15$ liters & $15(21.4 \%)$ \\
$\geq 16$ liters & $4(5.7 \%)$ \\
\hline
\end{tabular}

\section{Results}

For reliability and validity, this study use Narasimhan and Jayaram (1998) guideline. The researcher calculates the Cronbach's alpha $(\alpha)$, composite reliability $(\mathrm{CR})$ and factor loading to determine the reliability of each item. Table 2 show the results of FA, Cronbach's alpha and composite reliability. The items used for measurement had higher loading more than 0.5 . All constructs used in this study had value of CR and $\alpha$ above the required cutoff stipulated in study of (Lance, Butts, \& Michels, 2006). The value of AVE indicated in Table 2 imply that convergent validity is adhered in this study. Table 2 show the measurement of scale with reliability and validity. 
Table2. Measurement, FL, CA, CR and AVE

\begin{tabular}{|c|c|c|c|c|}
\hline \multirow[t]{2}{*}{ Measurements } & \multirow[t]{2}{*}{ Factor Loading } & \multirow[b]{2}{*}{$\alpha$} & \multirow[b]{2}{*}{$\mathrm{CR}$} & \multirow[b]{2}{*}{ AVE } \\
\hline & & & & \\
\hline Supply chain constraints & & & & \\
\hline Processing facilities & & 0.66 & 0.829 & 0.6187 \\
\hline PF1: Seasonality in supply & 0.750 & & & \\
\hline PF2: Capacity of facility & 0.855 & & & \\
\hline PF3: Facility breakdowns & 0.705 & & & \\
\hline Storage facilities & & $0.91^{\prime}$ & 0.948 & 0.859 \\
\hline SF1: Poor hygienic conditions & 0.938 & & & \\
\hline SF2: Spoilage of milk on transit & 0.893 & & & \\
\hline SF3: Inadequate milk handling equipment's & 0.948 & & & \\
\hline Transportation system and physical infrastructures & & 0.902 & 0.939 & 0.837 \\
\hline TPI1: Poor rough roads & 0.943 & & & \\
\hline TPI2: Lack of collection centres & 0.878 & & & \\
\hline TPI3: Lack of electricity & 0.921 & & & \\
\hline Distribution and delivery system & & 0.58 & 0.797 & 0.570 \\
\hline DDS1: Limited distribution channels & 0.851 & & & \\
\hline DDS2: Unreliable delivery & 0.639 & & & \\
\hline DDS3: Distribution barricades & 0.759 & & & \\
\hline Access to market & & 0.75 & 0.871 & 0.694 \\
\hline AM1: Asymmetry of information & 0.779 & & & \\
\hline AM2: Lack of reliable market & 0.831 & & & \\
\hline AM3: Unfavorable price from traders & 0.885 & & & \\
\hline Sustainability Performance & & 0.510 & 0.750 & 0.508 \\
\hline SP1: Flexibility in delivering and extra volume at point of sales & 0.526 & & & \\
\hline SP2: Responsiveness in delivery in terms of arranged point of sale & 0.813 & & & \\
\hline SP3: Quality of the product, packaging, storage and delivery & 0.766 & & & \\
\hline
\end{tabular}

This study used regression analysis to determine the constraints that affect sustainability performance in supply chain of dairy products in Tanzania. Table 3 summarized the regression results and descriptive results. The unstandardized coefficient of processing facilities $(B=-0.338, \mathrm{SE}=0.201, t=-1.678, p<0.10)$, access to market $(B=1.410, \mathrm{SE}=0.263, t=5.367, p<0.001)$, distribution and delivery system $(B=0.235, \mathrm{SE}=0.124, t=1.896$, $p<0.10)$, storage facilities $(B=-0.899, \mathrm{SE}=0.342, t=-2.632, t=-0.574, p<0.01)$ and transportation system and physical infrastructures $(B=-0.140, \mathrm{SE}=0.243, t=-0.574, p>0.05)$. The regression revealed a significant result for Processing facilities $\left(\mathrm{X}_{1}\right)$, Access to market $\left(\mathrm{X}_{2}\right)$, Distribution and delivery system $\left(\mathrm{X}_{3}\right)$, and Storage facilities $\left(\mathrm{X}_{4}\right)$. In this study Transportation system and physical infrastructures $\left(\mathrm{X}_{5}\right)$ was found insignificant. Surprising Processing facilities $\left(\mathrm{X}_{1}\right)$ and Storage facilities $\left(\mathrm{X}_{4}\right)$ were found with negative unstandardized coefficient which imply as the worsen constraints in supply chain of dairy products in Northern regions of Tanzania. The study proposed the following supply chain equation: $S C P=-0.338 X_{1}+1.410 X_{2}+0.235 X_{3}-0.899 X_{4}$. Table 3. Regression results and descriptive statistics

\begin{tabular}{|c|c|c|c|c|c|}
\hline Variables & B & SE & $\mathbf{t}$ & Mean & S. D \\
\hline (Constant) & $1.486^{* * *}$ & 0.244 & 6.080 & & \\
\hline Processing facilities $\left(\mathrm{X}_{1}\right)$ & $-0.338 \dagger$ & 0.201 & -1.678 & 1.38 & 0.496 \\
\hline Access to market $\left(\mathrm{X}_{2}\right)$ & $1.410 * * *$ & 0.263 & 5.367 & 1.54 & 0.678 \\
\hline Distribution and delivery system $\left(\mathrm{X}_{3}\right)$ & $0.235 \dagger$ & 0.124 & 1.896 & 1.60 & 0.602 \\
\hline Storage facilities $\left(\mathrm{X}_{4}\right)$ & $-0.899 * *$ & 0.342 & -2.632 & 1.51 & 0.690 \\
\hline $\begin{array}{l}\text { Transportation system and physical } \\
\text { infrastructures }\left(\mathrm{X}_{5}\right)\end{array}$ & -0.140 & 0.243 & -0.574 & 1.52 & 0.711 \\
\hline $\mathrm{R}^{2}$ & & 0.182 & & & \\
\hline Adjusted $\mathrm{R}^{2}$ & & 0.154 & & & \\
\hline$\Delta \mathrm{R}^{2}$ & & 0.182 & & & \\
\hline Durbin-Watson & & 0.368 & & & \\
\hline $\mathrm{F}$ & & $6.500 * * *$ & & & \\
\hline
\end{tabular}

Notes: $† \mathrm{p}<0.10 ; * \mathrm{p}<0.05 ; * * \mathrm{p}<0.01 ; * * * \mathrm{p}<0.001$

\section{Discussions}

The aim of this study was to investigate the sustainability performance in supply chain of dairy products through 
examining the dairy sector constraints using value chain approach in Tanzania. Findings from this study have revealed that there is a growing concern on the sustainability performance of dairy sector in Tanzania as the sector is subjected to many supply chain constraints and impediments (Table 3). Despite the paramount importance of this sector and contribution of smallholder dairy farming in Tanzania (E. S. Swai \& Karimuribo, 2011), supply chain constraints hinder the growing of smallholder dairy farming in Northern region of Tanzania to the large extant.

The findings show that processing facilities, access to market, distribution and delivery system, storage facilities are the main enormous supply chain constraints which affect the sustainability performance of diary sector in Tanzania. This findings are consistent with (Eskola, 2005; Kilelu et al., 2017; Kivaria et al., 2006; Kurwijila et al., 2006; Ruteri \& Xu, 2009; Schoder et al., 2013). Surprisingly, this study found that transportation and physical infrastructures is not a challenge in Northern regions which is contrary to study of Jeckoniah et al. (2013). This is attested by this participant: Although some of the smallholder's farmers stayed and worked in interior areas but to the large extant government has provide us with effective infrastructures specifically the road which pass in Simanjiro district and go to Arusha municipal (Focus group participant).

\section{Conclusions, recommendations, limitations and future research}

\subsection{Conclusion}

In conclusion, this study concurred with the on-going debate about the concern of sustainability in agri-business diary sector in developing countries. The debate of agri-cultural sustainability has dominated over the past decades where majority of studies focused on the environmental paradigm like climate change, this study provides the dimensions on the supply chain perspective. The study underpins the importance of different policy makers like ministry of agriculture and livestock to invest on eliminating the supply chain constraints associated with diary sector elaborated in previous part. This study provides quantitative evidence about the impediments and stabling blocks which affect the smallholders dairy sector in Northern region of Tanzania. For instance, inadequate and poor processing facilities of dairy products are dominant challenges for the sustainability of this sector in this region. Presently most of the processing centres in Simanjiro and Arusha are working at less than $12 \%$ of the installed capacity. Another enormous challenge for small holders' farmers of dairy products is access to market like asymmetry of information and lack of capital to access markets for selling their dairy products etc. In this study, storage of dairy products is seemed to be a problem to most emerging smallholder farmers in Tanzania. In additional to that is poor distribution and delivery system. Majority of smallholder farmers like Maasai used a local means like bicycles over long distance for distribution and delivery for their milk for sale at collection centres in Simanjiro and Arusha municipal.

\subsection{Recommendations}

On the basis of this study, we recommend to all stakeholders including policy makers, smallholders' farmers and entrepreneurs in dairy sector to take appropriate actions in order to eliminate the constraints in the downward and upward stream of supply chain. In order to ensure sustainable performance of dairy sector in Tanzania, a multidisciplinary approach, value chain techniques, diverse strategies and dialogues involving all key actors like the LGA's, civil society, respective ministries, smallholders' farmers, processing firms, and dairy entrepreneurs should be comprehensive discussed and implemented.

\subsection{Limitations and future research}

Although this study contributes to the extant literature in sustainable dairy supply chain, it also has some limitations. First, data collected using a mixed method of cross-sectional survey and focus group discussions which are both subjected to some limitations. Future studies should complement this by conducting longitudinal studies instead of cross-sectional survey which didn't take onboard the dynamic nature of dairy sector. Second, generalizability of this study should be taken with great cautions as the data was collected in one district of Tanzania. Future studies should collect data in more than one district with diverse diary activities. Finally, the gender imbalance should also be acknowledged. The study was dominated by women's which could imposed some gender biasness. Future studies should try to incorporate both gender to the study in order to bridge the social and economic inequality.

\section{References}

Ahmed, Mohamed AM, Ehui, Simeon, \& Assefa, Yemesrach. (2004). Dairy development in Ethiopia: Intl Food Policy Res Inst.

Anderson, Jock R. (2019). Concepts of Food Sustainability. In P. Ferranti, E. M. Berry \& J. R. Anderson (Eds.), Encyclopedia of Food Security and Sustainability (pp. 1-8). Oxford: Elsevier.

Bhagat, Deepak, \& Dhar, UR. (2011). Agriculture Supply Chain Management: A Review. IUP Journal of Supply Chain Management, 8(3). 
Binder, Claudia R, Schmid, Allan, \& Steinberger, JK. (2012). Sustainability solution space of the Swiss milk value added chain. Ecological Economics, 83, 210-220.

Bingi, S, \& Tondel, F. (2015). Recent developments in the dairy sector in Eastern Africa: Towards a regional policy framework for value chain development. Economic Centre for Development Policy Management Briefing Note, 78.

Bolwig, Simon, Ponte, Stefano, Du Toit, Andries, Riisgaard, Lone, \& Halberg, Niels. (2010). Integrating poverty and environmental concerns into value-chain analysis: a conceptual framework. Development policy review, 28(2), 173-194.

Bolwig, Simon, Ponte, Stefano, Riisgaard, Lone, du Toit, Andries, \& Halberg, Niels. (2013). A methodology for integrating developmental concerns into value chain analysis and interventions Markets and Rural Poverty (pp. 43-68): Routledge.

Bourlakis, Michael, Maglaras, George, Gallear, David, \& Fotopoulos, Christos. (2014). Examining sustainability performance in the supply chain: The case of the Greek dairy sector. Industrial Marketing Management, 43(1), 56-66. doi: https://doi.org/10.1016/j.indmarman.2013.08.002

Chang, TFM, Droli, M, \& ISEPI, L. (2014). Does smart agriculture go downstream in the supply chain? Italian Journal of Food Science, 26(4).

Charles Urassa, Goodluck. (2014). The effect of the regulatory framework on the competitiveness of the dairy sector in Tanzania. International Journal of Public Sector Management, 27(4), 296-305.

Christopher, Martin. (2016). Logistics \& supply chain management: Pearson UK.

Crain, David W, \& Abraham, Stan. (2008). Using value-chain analysis to discover customers' strategic needs. Strategy \& Leadership, 36(4), 29-39.

Dahlström, Kristina, \& Ekins, Paul. (2006). Combining economic and environmental dimensions: Value chain analysis of UK iron and steel flows. Ecological Economics, 58(3), 507-519.

Ding, Huiping, Fu, Yanan, Zheng, Lucy, \& Yan, Zhu. (2019). Determinants of the competitive advantage of dairy supply chains: Evidence from the Chinese dairy industry. International Journal of Production Economics, 209, 360-373. doi: https://doi.org/10.1016/j.ijpe.2018.02.013

Donaldson, Krista M, Ishii, Kosuke, \& Sheppard, Sheri D. (2006). Customer value chain analysis. Research in Engineering Design, 16(4), 174-183.

El Semary, Nermin Adel. (2019). Algae and Chain Aquaculture: An Approach Towards Sustainable Agriculture. In A. M. Negm \& M. Abu-hashim (Eds.), Sustainability of Agricultural Environment in Egypt: Part II: Soil-Water-Plant Nexus (pp. 311-323). Cham: Springer International Publishing.

Eskola, Elina. (2005). Agricultural marketing and supply chain management in Tanzania.

Faulconbridge, James. (2007). Global shift. Mapping the changing contours of the world economy Peter Dicken: Oxford University Press.

Fearne, Andrew, Garcia Martinez, Marian, \& Dent, Benjamin. (2012). Dimensions of sustainable value chains: implications for value chain analysis. Supply Chain Management: An International Journal, 17(6), 575-581.

Francis, Mark, Simons, David, \& Bourlakis, Michael. (2008). Value chain analysis in the UK beef foodservice sector. Supply chain management: an international journal, 13(1), 83-91.

Gafsi, Mohamed, Legagneux, Bruno, Nguyen, Geneviève, \& Robin, Patrice. (2006). Towards sustainable farming systems: Effectiveness and deficiency of the French procedure of sustainable agriculture. Agricultural Systems, 90(1), 226-242. doi: https://doi.org/10.1016/j.agsy.2006.01.002

Ghadge, Abhijeet, Kaklamanou, Merilena, Choudhary, Sonal, \& Bourlakis, Michael. (2017). Implementing environmental practices within the Greek dairy supply chain: Drivers and barriers for SMEs. Industrial Management \& Data Systems, 117(9), 1995-2014. doi: 10.1108/IMDS-07-2016-0270

Giuliani, Elisa, Pietrobelli, Carlo, \& Rabellotti, Roberta. (2005). Upgrading in global value chains: lessons from Latin American clusters. World development, 33(4), 549-573.

Glover, J. L., Champion, D., Daniels, K. J., \& Dainty, A. J. D. (2014). An Institutional Theory perspective on sustainable practices across the dairy supply chain. International Journal of Production Economics, 152, 102-111. doi: https://doi.org/10.1016/j.ijpe.2013.12.027

Hawkes, C., Blouin, C., Henson, S., Drager, N., \& Dubé, L. (2009). Trade, Food, Diet and Health: Perspectives and Policy Options: Wiley.

Henderson, Jeffrey, Dicken, Peter, Hess, Martin, Coe, Neil, \& Yeung, Henry Wai-Chung. (2002). Global production networks and the analysis of economic development. Review of international political economy, 9(3), 436-464.

Hergert, Michael, \& Morris, Deigan. (1989). Accounting data for value chain analysis. Strategic Management Journal, 10(2), 175-188.

Hillbom, Ellen. (2011). Farm intensification and milk market expansion in Meru, Tanzania. African Studies Review, 54(1), 145-165.

Howieson, Janet, Lawley, Meredith, \& Hastings, Kathleen. (2016). Value chain analysis: an iterative and 
relational approach for agri-food chains. Supply Chain Management: An International Journal, 21(3), 352362.

Humphrey, John, \& Schmitz, Hubert. (2002). Developing country firms in the world economy: Governance and upgrading in global value chains.

Jeckoniah, JN, Mdoe, NSY, \& Nombo, CN. (2013). Mapping of gender roles and relations along onion value chain in northern Tanzania.

Katjiuongua, H, \& Nelgen, S. (2014). Tanzania smallholder dairy value chain development: Situation analysis and trends ILRI Project Report. Nairobi, Kenya: ILRI.

Kazancoglu, Yigit, Ozkan-Ozen, Yesim Deniz, \& Ozbiltekin, Melisa. (2018). Minimizing losses in milk supply chain with sustainability: An example from an emerging economy. Resources, Conservation and Recycling, 139, 270-279. doi: https://doi.org/10.1016/j.resconrec.2018.08.020

Kilelu, Catherine, Klerkx, Laurens, Omore, Amos, Baltenweck, Isabelle, Leeuwis, Cees, \& Githinji, Julius. (2017). Value Chain Upgrading and the Inclusion of Smallholders in Markets: Reflections on Contributions of Multi-Stakeholder Processes in Dairy Development in Tanzania. The European Journal of Development Research, 29(5), 1102-1121. doi: 10.1057/s41287-016-0074-z

Kimaro, Esther G, Mor, Siobhan M, \& Toribio, Jenny-Ann LML. (2018). Climate change perception and impacts on cattle production in pastoral communities of northern Tanzania. Pastoralism, 8(1), 19.

Kivaria, FM, Noordhuizen, JPTM, \& Kapaga, AM. (2006). Prospects and constraints of smallholder dairy husbandry in the Dar es Salaam region, Tanzania. Outlook on AGRICULTURE, 35(3), 209-215.

Kline, Carol S, Joyner, Leah Elizabeth, Kirchoff, Jon F, Crawford, Alleah, Jilcott Pitts, Stephanie, Wall-Bassett, Elizabeth, .. . Dunning, Rebecca. (2016). Gaps and barriers along the North Carolina agri-food value chain. British Food Journal, 118(2), 301-317.

Kurwijila, Lusato R, \& Henriksen, Jorgen. (1995). Milk supply to urban centres in Tanzania with particular reference to the city of Dar Es Salaam. Paper presented at the Proceedings FAO Workshop on Market Orientation of Small Scale Milk producers and their Organisations, Morogoro.

Kurwijila, Lusato R, Omore, A, Staal, S, \& Mdoe, NSY. (2006). Investigation of the risk of exposure to antimicrobial residues present in marketed milk in Tanzania. Journal of Food Protection, 69(10), 24872492.

Kurwijila, Lusato R, Omore, Amos O, \& Grace, Delia. (2012). Tanzania dairy industry overview 2012.

Lance, Charles E, Butts, Marcus M, \& Michels, Lawrence C. (2006). The sources of four commonly reported cutoff criteria: What did they really say? Organizational research methods, 9(2), 202-220.

Levin, Kate Ann. (2006). Study design III: Cross-sectional studies. Evidence-based dentistry, 7(1), 24.

Lukuyu, June M, Blanchard, Richard E, \& Rowley, Paul N. (2019). A risk-adjusted techno-economic analysis for renewable-based milk cooling in remote dairy farming communities in East Africa. Renewable energy, 130, 700-713.

Maleko, David, Msalya, George, Mwilawa, Angello, Pasape, Liliane, \& Mtei, Kelvin. (2018). Smallholder dairy cattle feeding technologies and practices in Tanzania: failures, successes, challenges and prospects for sustainability. International journal of agricultural sustainability, 16(2), 201-213.

Manyilizu, Wilbert, Mdegela, Robinson, Kazwala, Rudovick, Nonga, Hezron, Muller, Mette, Lie, Elisabeth, ... Lyche, Jan. (2016). Association of long-term pesticide exposure and biologic parameters in female farm workers in Tanzania: A cross sectional study. Toxics, 4(4), 25.

Mentzer, John T, DeWitt, William, Keebler, James S, Min, Soonhong, Nix, Nancy W, Smith, Carlo D, \& Zacharia, Zach G. (2001). Defining supply chain management. Journal of Business logistics, 22(2), 1-25.

Mor, Rahul S., Bhardwaj, Arvind, \& Singh, Sarbjit. (2018). Benchmarking the interactions among performance indicators in dairy supply chain: An ISM approach. Benchmarking: An International Journal, 25(9), 38583881. doi: 10.1108/BIJ-09-2017-0254

Narasimhan, Ram, \& Jayaram, Jayanth. (1998). Causal linkages in supply chain management: an exploratory study of North American manufacturing firms. Decision sciences, 29(3), 579-605.

Nelgen, Signe, \& Strutt, Anna. (2014). Evolving Opportunities for the Tanzanian Dairy Industry: An Analysis of Potential Impacts.

Nicholson, Charles F, Gómez, Miguel I, \& Gao, Oliver H. (2011). The costs of increased localization for a multiple-product food supply chain: Dairy in the United States. Food Policy, 36(2), 300-310.

Njombe, AP, Msanga, Y, Mbwambo, N, \& Makembe, N. (2011). The Tanzania dairy industry: Status, opportunities and prospects. Paper presented at the Ministry of Livestock and Fisheries Development. African Dairy Conference and Exhibition, Dar es Salaam, Tanzania.

Ojija, Fredrick, Abihudi, Siri, Mwendwa, Beatus, Leweri, Cecilia M, \& Chisanga, Kafula. (2017). The Impact of Climate Change on Agriculture and Health Sectors in Tanzania: A review. International Journal of Environment, Agriculture and Biotechnology, 2(4).

Omambia, CEVEN SHEMSANGA, \& Gu, Yansheng. (2010). The cost of climate change in Tanzania: impacts 
and adaptations. Journal of American Science, 6(3).

Prakash, Surya, Soni, Gunjan, Rathore, Ajay Pal Singh, \& Singh, Shubhender. (2017). Risk analysis and mitigation for perishable food supply chain: a case of dairy industry. Benchmarking: An International Journal, 24(1), 2-23. doi: 10.1108/BIJ-07-2015-0070

Rabelo, Luis, Eskandari, Hamidreza, Shaalan, Tarek, \& Helal, Magdy. (2007). Value chain analysis using hybrid simulation and AHP. International Journal of Production Economics, 105(2), 536-547.

Rose, David C., Sutherland, William J., Barnes, Andrew P., Borthwick, Fiona, Ffoulkes, Charles, Hall, Clare, .. . Dicks, Lynn V. (2019). Integrated farm management for sustainable agriculture: Lessons for knowledge exchange and policy. Land Use Policy, 81, 834-842. doi: https://doi.org/10.1016/j.landusepol.2018.11.001

Rudenko, Inna, Grote, Ulrike, \& Lamers, John. (2008). Using a value chain approach for economic and environmental impact assessment of cotton production in Uzbekistan Environmental problems of central Asia and their economic, social and security impacts (pp. 361-380): Springer.

Ruteri, Juma Makweba, \& Xu, Qi. (2009). Supply chain management and challenges facing the food industry sector in Tanzania. International Journal of Business and Management, 4(12), 70-80.

Savino, Matteo M, Manzini, Riccardo, \& Mazza, Antonio. (2015). Environmental and economic assessment of fresh fruit supply chain through value chain analysis. A case study in chestnuts industry. Production Planning \& Control, 26(1), 1-18.

Schoder, Dagmar, Maichin, Andreas, Lema, Benedict, \& Laffa, John. (2013). Microbiological quality of milk in Tanzania: from Maasai stable to African consumer table. Journal of food protection, 76(11), 1908-1915.

Sewando, Ponsian T., Mutabazi, Khamaldin D., \& Mdoe, Ntengua Y. S. (2016). Vulnerability of agro-pastoral farmers to climate risks in northern and central Tanzania. Development Studies Research, 3(1), 11-24. doi: $10.1080 / 21665095.2016 .1238311$

Sharma, Amit, \& Christie, Iain T. (2010). Performance assessment using value-chain analysis in Mozambique. International Journal of Contemporary Hospitality Management, 22(3), 282-299.

Svensson, Göran, \& Wagner, Beverly. (2012). Implementation of a sustainable business cycle: the case of a Swedish dairy producer. Supply Chain Management: An International Journal, 17(1), 93-97.

Swai, Emmanuel S, \& Karimuribo, Esron D. (2011). Smallholder dairy farming in Tanzania: Current profiles and prospects for development. Outlook on AGRICULTURE, 40(1), 21-27.

Swai, ES, French, NP, Karimuribo, ED, Fitzpatrick, JL, Bryant, MJ, Brown, PE, \& Ogden, NH. (2005). Spatial and management factors associated with exposure of smallholder dairy cattle in Tanzania to tick-borne pathogens. International journal for parasitology, 35(10), 1085-1096.

Taylor, David H. (2005). Value chain analysis: an approach to supply chain improvement in agri-food chains. International Journal of Physical Distribution \& Logistics Management, 35(10), 744-761. doi: 10.1108/09600030510634599

Temu, P.E. (2011). Tanzania: My Country as I See It: AuthorHouse.

URT. (2012). NATIONAL SAMPLE CENSUS OF AGRICULTURE 2007/2008 SMALL HOLDER AGRICULTURE. REGIONAL REPORT-MANYARA REGION, 5.

Vasileiou, K, \& Morris, J. (2006). The sustainability of the supply chain for fresh potatoes in Britain. Supply Chain Management: An International Journal, 11(4), 317-327.

Watkiss, P, Downing, T, Dyszynski, J, Pye, S, Savage, M, Goodwin, J, . . Lynn, S. (2011). The economics of climate change in the United Republic of Tanzania: Global Climate Adaptation Partnership (GCAP). 